Article

\title{
Satellite Detection Limitations of Sub-Canopy Smouldering Wildfires in the North American Boreal Forest
}

\author{
Joshua M. Johnston ${ }^{1,2, *(\mathbb{D})}$, Lynn M. Johnston ${ }^{1} \mathbb{1}^{\mathbb{C}}$, Martin J. Wooster ${ }^{2,3} \mathbb{( B}^{\mathbb{C}}$, Alison Brookes ${ }^{1}$, \\ Colin McFayden ${ }^{4}$ and Alan S. Cantin ${ }^{1}$ \\ 1 Canadian Forest Service, Great Lakes Forestry Centre, 1219 Queen St. E., Sault Ste. Marie, \\ ON P6A 2E5, Canada; Lynn.Johnston@canada.ca (L.M.J.); Alison.Brookes@canada.ca (A.B.); \\ Alan.Cantin@canada.ca (A.S.C.) \\ 2 Department of Geography, King's College London, Strand, London WC2R 2LS, UK; \\ Martin.Wooster@kcl.ac.uk \\ 3 Natural Environment Research Council (NERC), National Centre for Earth Observation (NCEO) at King's \\ College London, Strand, London WC2R 2LS, UK \\ 4 Ontario Ministry of Natural Resources \& Forestry, Aviation Forest Fire \& Emergency Services, Dryden Fire \\ Management Headquarters, P.O. Box 850, Dryden, ON P8N 2Z5, Canada; Colin.McFayden@ontario.ca \\ * Correspondence: Joshua.Johnston@canada.ca; Tel.: +1-705-541-5548
}

Received: 27 June 2018; Accepted: 8 August 2018; Published: 10 August 2018

\begin{abstract}
We develop a simulation model for prediction of forest canopy interception of upwelling fire radiated energy from sub-canopy smouldering vegetation fires. We apply this model spatially across the North American boreal forest in order to map minimum detectable sub-canopy smouldering fire size for three satellite fire detection systems (sensor and algorithm), broadly representative of the Moderate Resolution Imaging Spectroradiometer (MODIS), Sea and Land Surface Temperature Radiometer (SLSTR) and Visible Infrared Imaging Radiometer Suite (VIIRS). We evaluate our results according to fire management requirements for "early detection" of wildland fires. In comparison to the historic fire archive (Canadian National Fire Database, 1980-2017), satellite data with a $1000 \mathrm{~m}$ pixel size used with an algorithm having a minimum MWIR channel BT elevation threshold of 5 and $3 \mathrm{~K}$ above background (e.g., MODIS or SLSTR) proves incapable of providing a sub- 0.2 ha smouldering fire detection $70 \%$ and $45 \%$ of the time respectively, even assuming that the sensor overpassed the relevant location within the correct time window. By contrast, reducing the pixel area by an order of magnitude (e.g., $375 \mathrm{~m}$ pixels of VIIRS) and using a $3.5 \mathrm{~K}$ active fire detection threshold offers the potential for successfully detecting all fires when they are still below 0.2 ha. Our results represent a 'theoretical best performance' of remote sensing systems to detect sub-canopy smoldering fires early in their lifetime.
\end{abstract}

Keywords: wildfire detection; remote sensing; infrared; forest canopy; leaf area index (LAI)

\section{Introduction}

In wildland fire management, fire detection plays an important role in the goal of minimizing the total cost of actioning a fire plus the potential net loss from destruction [1-3]. There are two general systems for wildland fire detection: direct detection systems and indirect detection systems. Direct detection systems are systems where a fire management agency coordinates actions for the primary purpose of discovering and reporting fires (e.g., a fire tower network, aerial detection patrols). Indirect detection systems are systems where detection and reporting is carried out passively (e.g., public fire reports, suppression aircraft reporting en-route); however, fire agencies do support 
these indirect systems, for example by maintaining a public reporting hotline or training firefighters to scan for and report fires while on dispatch.

Direct detection systems have the potential to improve the effectiveness of fire suppression when fires are detected and reported when they are still small, particularly in areas where fires are less likely to be reported indirectly (e.g., using direct aerial patrol vs. indirect public detection). Under the right conditions, fires that are found while they remain small are less likely to escape control efforts $[2,4]$, which is why quick initial attack is a conventional fire management strategy to minimize suppression costs and subsequent losses [3,5-7]. Detection success is therefore characterized by the ability of the fire management agency to detect a fire while it is still small enough to enable initial attack 'success'. Initial attack success has no national standard definition [4] and its operational definition varies across provincial/territorial fire agencies. In general, initial attack success is evaluated according to various indicators of fire containment or control after a certain time since detection. For example, Ontario requires a fire to be classified as 'Being Held' by noon the day following detection, or final fire size is $\leq 4.0 \mathrm{ha}$, or the fire remains within initial boundaries [8]. However, not all fires that are detected receive initial attack; some are left on the landscape to fulfill their natural role in the ecosystem and require a different management approach (e.g., monitoring only, or limited value protection). This form of fire management is more common at northern latitudes and requires less stringent fire detection criteria [9].

Fire detection can also be accomplished through satellite remote sensing of post-fire residual burn scars [10-12], or of active fire using thermal signatures or so called active fire "hotspots" [13]. Active fire detection algorithms for satellite systems come in a variety of forms, such as the science grade products (which are released at a greater data latency) and the "rapid response" products which are made available within hours of the satellite overpass [14-16]. Geostationary satellites provide the best temporal coverage for fire monitoring and science grade products are often produced very rapidly after the imaging has occurred but they typically fail to detect smaller and/or very low intensity fires [17]. Imagers on finer spatial resolution Low-Earth Orbiting (LEO) satellites are typically better able to detect these fires, albeit only when the relevant satellite is overpassing the location. Notably, even LEO satellites are not capable of detecting all actively burning small fires [11,18]. Detection capabilities maybe degraded further in the dense forests such as the Canadian boreal forest, where thick canopies may attenuate upwelling radiation from sub-canopy fires. Such 'canopy interception' of surface fire radiance has been a known issue since the advent of satellite fire detection [19] but has only begun to be investigated in any detail much more recently [20]. Of particular interest are situations where surface fires produce a source of intense infrared (IR) thermal radiation close to the forest floor and where limited or no crown fire activity takes place, leaving the forest canopy fully or partially intact. Given that fire radiative power (FRP) retrievals work via measurement of top-of-atmosphere thermal signals (e.g., [21,22]), such 'canopy interception' of fire-emitted IR radiation has the potential to cause FRP to be underestimated. While such underestimation has been counteracted somewhat by new methods to relate smoke-aerosol emissions to satellite observed FRP (e.g., [23,24]), the interception of the upwelling thermal radiation by the canopy can still impact the initial active fire detection. Fortunately, the effect of forest canopy interception on downwelling solar radiation and its impact on light levels on the forest floor is well documented (e.g., [25-27]), providing a basis for landscape scale modelling of forest canopy effects on surface fire radiance.

Presently it is not certain if satellite fire detection is capable of detecting sub-canopy smouldering wildfires when they are "small enough" to serve the needs of operational fire management in Canada. In this study, we model the minimum smouldering area needed for detection by operational LEO fire detection systems. We consider three LEO detection systems: Moderate Resolution Imaging Spectroradiometer (MODIS), Sea and Land Surface Temperature Radiometer (SLSTR) and Visible Infrared Imaging Radiometer Suite (VIIRS). Using experimental measurements of heat sources viewed through vegetation canopy surrogates, we develop a model for boreal forest canopy thermal radiance interception and we then apply this model to determine the minimum detectable sub-canopy 
smouldering fire area across the North American boreal forest. We discuss the results in the context of operational fire management requirements.

\section{Materials and Methods}

\subsection{Experimental Methods}

We used a laboratory experiment to empirically determine the amounts of fire-emitted upwelling thermal radiation that can be intercepted by a forest canopy. The experimental heat source was a set of flat-plate blackbodies (described elsewhere [28]). We set the heat source to a temperature of $673 \mathrm{~K}$ to approximate the temperature of smouldering combustion [29], as is typical for sub-canopy fires in the North American boreal forest. To measure the IR radiation, we used a tripod-mounted Agema 550 mid-wave infrared (MWIR) camera [21]; positioned $7 \mathrm{~m}$ away from the heat source. We monitored air temperature, relative humidity and atmospheric pressure throughout the investigation using a Kestrel weather station; ranging over $0.8-1.6^{\circ} \mathrm{C}, 62.7-68.1 \%$ and $97-99 \mathrm{kPa}$, respectively. These environmental conditions provided consistent and near perfect atmospheric transmission values in the MWIR spectral region for the duration of the experiment. The indoor setup also ensured that minimal ambient winds were experienced during the experiments.

We created an artificial forest canopy using white spruce (Picea glauca) boughs to experimentally measure canopy interception over a range of canopy cover conditions emulating the Canadian boreal forest. This experiment was performed mid-winter, so the foliar moisture content of the boughs used in this experiment was lower than what would be expected of a canopy during the summer months. Since foliar moisture could potentially affect canopy interception of IR radiation, we first rehydrated the boughs. We achieved this by cutting two white spruce trees (approximately $6 \mathrm{~m}$ in height), bringing them indoors (at $\sim 2{ }^{\circ} \mathrm{C}$ ) and placing their stems in water for a week. Similar methods of hydrating white spruce were tested by Van Wagner (1962), who found that foliar moisture levels were raised to 100-140\% gravimetric moisture content (as percent dry mass), values typically associated with live foliage [30].

Prior to obstructing the viewing path with the vegetation canopy, we collected thermal imagery of the blackbody heat source to establish baseline radiance. We constructed simulated vegetation 'canopies' from five wooden frames with fine gauge wire secured within them. We secured the white spruce boughs we had cut from the rehydrated trees in a homogeneous arrangement onto the wire of each frame. We hung the frames vertically in the optical path between the camera and the heat source to partly obscure the view of the heat source by the camera. Once the first frame was in place, we collected a further one hundred MWIR thermal images at a rate of $1 \mathrm{~Hz}$. We also collected matching visible wavelength imagery using a digital camera fit with a hemispherical lens from the viewpoint of the heat source. To increase the vegetation canopy density, we added a second frame of 'canopy' at a $60 \mathrm{~cm}$ horizontal distance from the first frame and we re-measured the heat source through this new, denser canopy. We repeated this process until all five frames were obstructing the thermal imager's view of the heat source (Figure 1). In this way, the effect of viewing the same heat source through a range of canopy densities was simulated. We continuously monitored the stability of the blackbody temperature with thermocouples to ensure the data reflected the reference imagery.

In order to quantitatively assess canopy cover, we employed the leaf area index (LAI) metric, a dimensionless parameter defined as the total one-sided foliage area per unit of ground surface area [31], including needle foliage in conifer stands [32]. In the present context, it is not the actual leaf area that is of interest, so much as the physical structure and spatial arrangement of the canopy elements which are known to control the absorption, reflectance, transmission and scattering of downwelling solar radiation when observed from the forest floor [33]. In modelling the attenuation of short- and long-wave radiation by forest canopies, Black et al. (1991) introduced the concept of effective LAI, which includes obstructions effecting downwelling radiation (e.g., tree boles, branches) [34]. This definition is appropriate for the current study, as it is simple and has the ability to generalize 
canopy structure over large areas typical of satellite pixel footprints (which we will use in this study); therefore, LAI here refers to the effective LAI. The artificial nature of the experimental conditions was not conducive for replicating more complex canopy attributes (e.g., bulk density, canopy closure or gap spacing) realistically. FRP transmittance through the canopy $\left(\mathrm{FRP}_{\text {trans }}\right)$ was thus calculated using:

$$
\mathrm{FRP}_{\text {trans }}=\operatorname{FRP}\left(\mathrm{e}^{-\alpha \mathrm{LAI}}\right)
$$

where FRP trans is the FRP transmitted through the canopy, FRP is the actual FRP below the canopy and $\alpha$ is an extinction coefficient empirically fit to the experimental data.

We analyzed the visible hemispherical images of the canopy screens using canopy gap analysis software [35] and calculated their effective LAI and related this to the amount of IR radiation reaching the camera, expressed as the observed FRP of the blackbody source and calculated using Stefan's Law rather than the MWIR radiance method commonly used with satellite datasets, since the blackbody temperature was near to the outer limit of the MWIR radiance method's applicability [21].

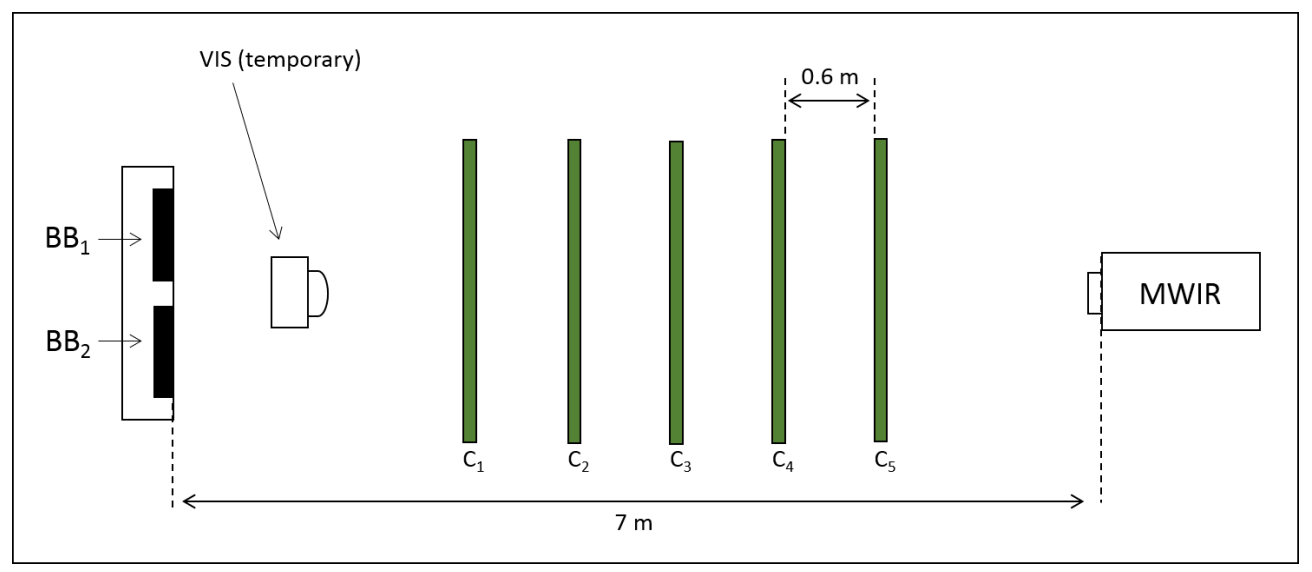

Figure 1. Layout for the canopy interception experiment. The panels (noted as $C_{i}$ ) are wooden frames with attached screens that supported the white spruce (Picea glauca) boughs used to obstruct the path of the thermal radiation that was emitted by the blackbodies $\left(\mathrm{BB}_{1}\right.$ and $\left.\mathrm{BB}_{2}\right)$. Canopy inferences was measured by inserting a visible camera in the location noted as "VIS camera" and collecting imagery of the screens.

\subsection{Modelling Methods}

Subsequent to the experimental work, we produced a landscape-scale simulation model of the canopy transmittance of IR radiation emitted from sub-canopy wildfires that can then be detected by satellite-based IR sensors (Figure 2). The degree of interception induced by the vegetation canopy was informed by the experimentally derived datasets discussed in Section 2.1. Through this simulation we produced a canopy transmittance model based on satellite-derived LAI data of the boreal forests of North America. The North American Boreal forest zone extent was taken from the FAO's ecofloristic zones [36]. Effective LAI across the study area was taken from 10-day MERIS composites of LAI in 2015 at $1 \mathrm{~km}$ resolution for May to October (one composite per month). We spatially aggregated LAI into a $3400 \mathrm{~km}^{2}(\sim 1 \times 1$ degree at mid-latitudes of Canada) hexagon grid which was created using the "Repeating Shapes" tool (v. 1.5.152) for ArcGIS [37]. The hexagon grid (and all spatial analysis in this paper) was performed using the WGS 1984/North Pole Lambert Azimuthal Equal Area Canada coordinate system. LAI varies spatially and temporally throughout the year, thus the need for full season data; Figure 3 a depicts this LAI data as a seasonal mean, aggregated into the hexagonal grid.

Using the gridded LAI composite data, we calculated the fractional FRP transmittance through the forest canopy based on the experimentally-derived transmittance through varying canopy LAI values (Equation (1)). This resulted in six transmittance maps, one for each month May to October. 


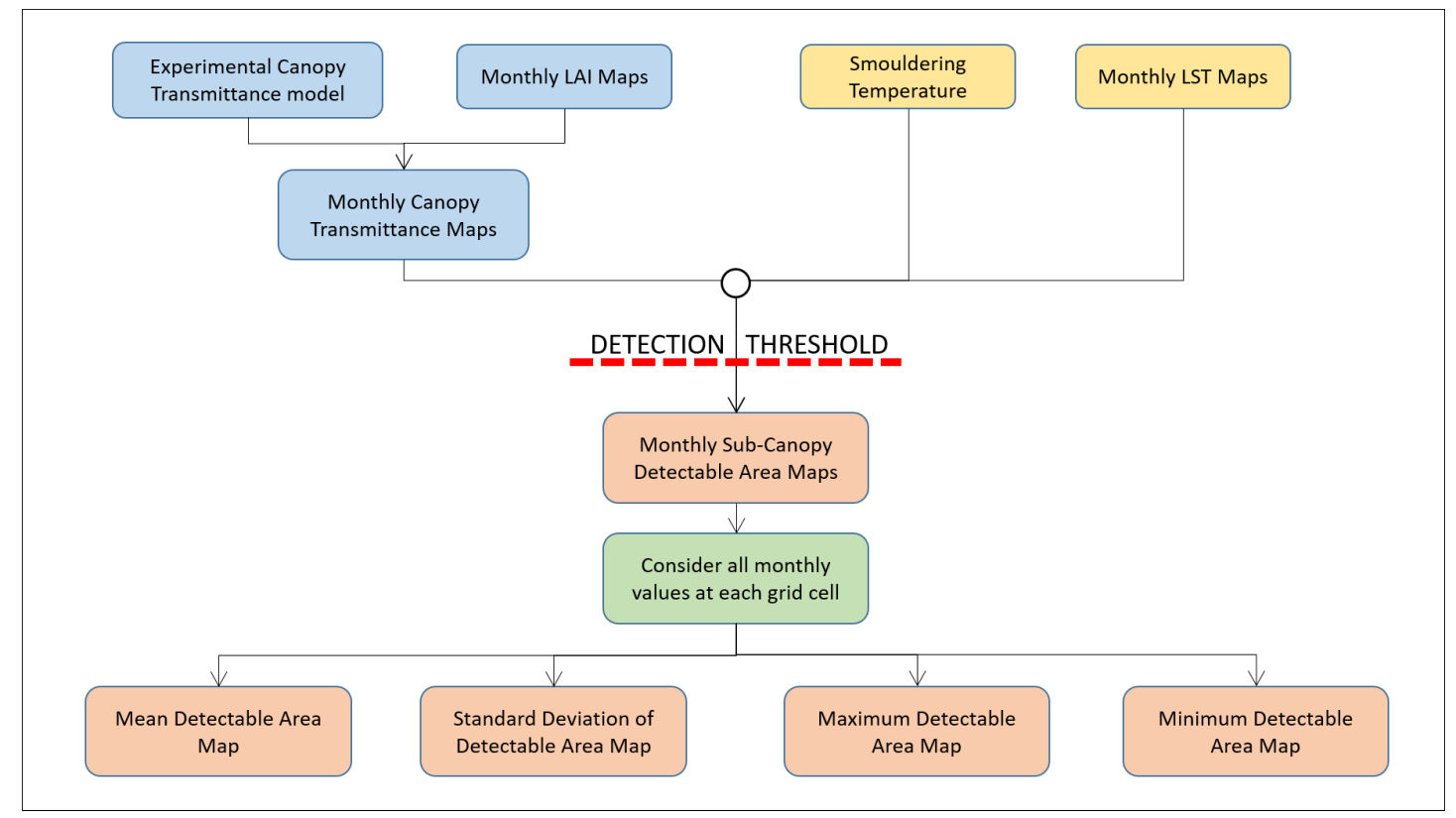

Figure 2. Flow chart describing the modelling process for creating spatial maps for sub-canopy detectable area). Spatial resolutions and detection thresholds changed as required to represent varying satellite systems.

To then determine the sub-canopy smouldering wildfire detection capability of various satellite instruments we used our calculated transmittance values to estimate the "minimum detectable fire area," that is, the smallest fire area required to raise the brightness temperature (BT) of a pixel above that of the surrounding ambient background by a certain threshold, since this is the basis of most active fire detection algorithms. To do this we first had to define the threshold criteria and we selected the minimum fire area required to trigger further pixel scrutiny in the active fire detection algorithms (sometimes called the 'potential fire pixel' thresholds [38]. The minimum criteria for potential fire pixel identification is a MWIR BT $3 \mathrm{~K}$ and $5 \mathrm{~K}$ above the local background temperature for SLSTR and MODIS Collection 6 respectively, [15,39]. A similar threshold of 3.5 standard deviations above the background temperature exists for pre-screening potential fire pixels with the VIIRS I-band [14]. In this study, we assume a standard deviation of $1 \mathrm{~K}$, giving VIIRS a threshold value of $3.5 \mathrm{~K}$. Detectable fire area was therefore modelled as the minimum fire area required to raise the pixel $\mathrm{BT}$ above these candidate fire pixel thresholds. Notably, these simulations do not necessarily reflect the performance of the specific satellite systems, simply the fire area required to trigger a potential fire pixel at their respective thresholds and spatial resolutions. Actual fire detection for these systems is also dependent on a number of additional contextual tests which may still categorize these pixels as false alarms. For this reason, our analysis focuses on the minimum theoretical fire area required to trigger a potential fire pixel for $1000 \mathrm{~m}$ pixels at 3 and $5 \mathrm{~K}$ detection thresholds and $375 \mathrm{~m}$ pixels at a $3.5 \mathrm{~K}$ threshold. This range of pixel sizes and minimum BT detection thresholds thus represents an envelope of situations that are indicative of real satellite observation detection limits, albeit we are not evaluating the detailed performance of specific active fire detection systems (which depend on factors beyond only a minimum BT detection threshold).

We next had to model both fire and background temperatures for calculation of minimum fire detectable area. For flaming combustion, a net fire temperature of $1000 \mathrm{~K}$ was used, which is lower than kinetic flame temperatures ( $1373 \mathrm{~K})$ [40] to account for loss due to potentially non-blackbody behavior at shorter flame lengths [28] and mixing of smouldering and flaming area. A smouldering temperature of $673 \mathrm{~K}$ was used [29] and was not lowered due to the consistently high emissivity of smouldering combustion, which emits not from a flame but from the hot surface [41]. In order to 
account for the non-linearity in the Planck function in the MWIR spectral band, both background and fire temperatures were converted into spectral radiance units $\left(\mathrm{W} \mathrm{m}^{-2} \mathrm{sr}^{-1} \mu \mathrm{m}^{-1}\right)$ and combined with the background radiance via the weighted average of their respective areas [42]. A depiction of this simulation is presented in Figure 4. Notably, detection sensitivity varies with background temperature and fire temperature. Background temperature values were obtained from MODIS LST data for May to October 2014 [43] and we spatially aggregated the data to the same hexagonal grid as for the LAI values (Figure 3b). These relationships were then used to calculate the minimum detectible area from the transmittance data for the entire study area. In summary, for each month (May to October), we created one gridded map of minimum detectable fire area for each of the three the three thresholds tested, $3 \mathrm{~K}$ and $5 \mathrm{~K}$ at $1 \mathrm{~km}$ pixels (e.g., indicative of SLSTR and MODIS) and $3.5 \mathrm{~K}$ for $375 \mathrm{~m}$ pixels (indicative of VIIRS).

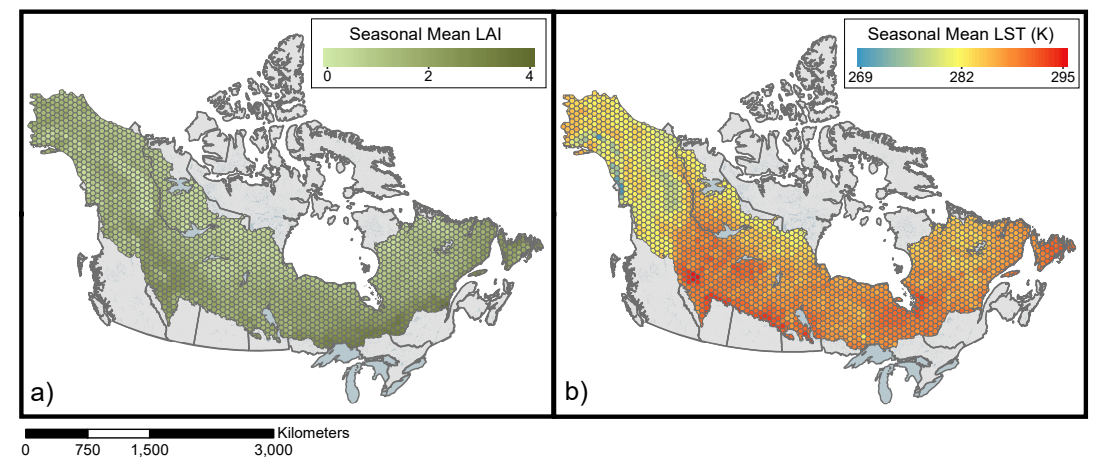

Figure 3. The two model parameters, shown spatially for the study area (North American boreal forest) as a seasonal (May-October) mean, with (a) showing seasonal mean effective leaf area index (LAI); and $(\mathbf{b})$ showing seasonal mean land surface temperature.

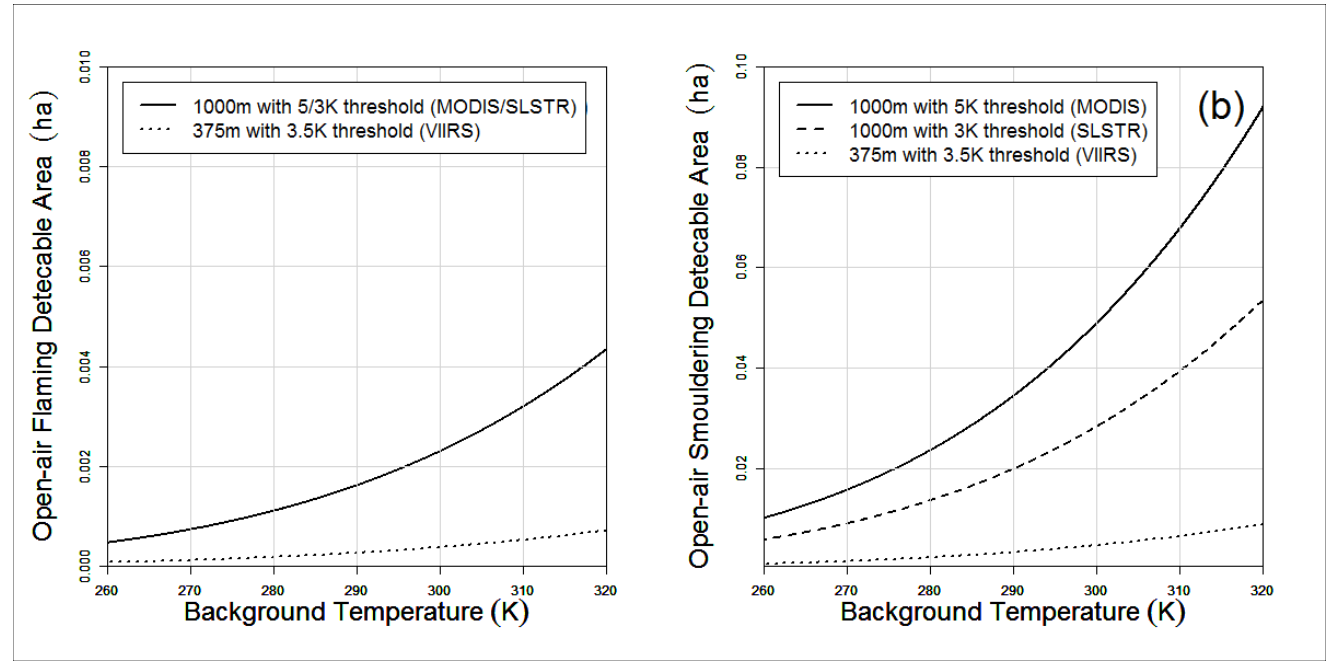

Figure 4. Open air minimum flaming (a) and smouldering (b) detectable area (ha) for $1000 \mathrm{~m}$ nadir facing pixels (MODIS and SLSTR; solid and dashed lines) and for the $375 \mathrm{~m}$ VIIRS I-Band (dotted line). Detection threshold were determined as the minimum mid-wave infrared (MWIR) spectral radiance increase due to smouldering combustion required for the candidate pixel to pass the pre-screening test in the respective fire detection algorithms [14,15,39]. Notably, due to the non-linearity of the MWIR band in the Planck function, the detectable area for flaming combustion is not very significantly impacted by the different thresholds applied for MODIS and SLSTR (a), this is not the case at smouldering temperatures (b). Regardless, in the absence of canopy obstruction all algorithms are capable of detecting both flaming and smouldering fires below the 0.2 ha threshold required for fire management. 


\subsection{Analysis Methods}

In order to establish a benchmark for detection performance required for initial attack, airborne fire discovery sizes of fires found by airborne detection in the province of Ontario were analyzed. The fires included in the analysis were those from 1997 to 2012, 1 April to 31 October inclusive, detected first from aircraft on fire patrol, inside the official fire regions. Figure 5 presents the distribution of these data; the median value of 0.2 ha was used as a performance benchmark (see Results Section).

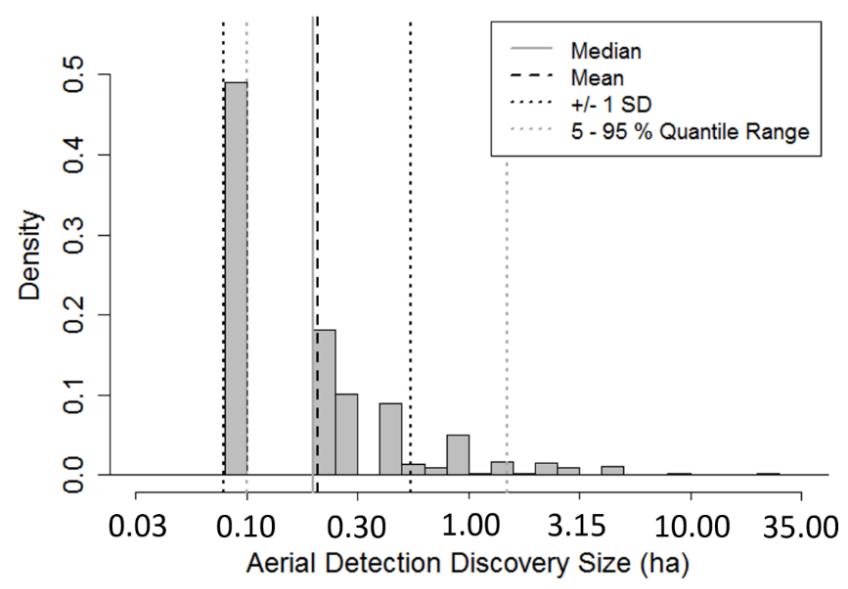

Figure 5. Log base normalized frequency distribution of wildfire discovery size (ha) from airborne detection patrols in Ontario between 1997 and 2012. The mean value is 0.47 with a standard deviation of 1.87 , the median is 0.20 and the 5 and $95 \%$ quantile ranges are 0.10 and 1.50 respectively. Discovery sizes are skewed significantly to smaller fires with $75 \%$ of fires being discovered below 0.3 ha.

To further evaluate the performance of the satellite sensors for fire detection, we investigated recent fire activity with respect to the locations where these sensors are capable of detecting the 0.2 ha benchmark fire size. Fire activity was evaluated within our study area with the number of fires from Canada's National Fire Database (NFDB) from 1980-2017 [44] (Figure 6). We evaluated the number of fires that are located within areas with minimum detectible areas of more than 0.2 ha, that is, those sub-canopy fires that would not have been detected given the sensor's detection threshold. This was done for each of the three thresholds tested, $5 \mathrm{~K}$ and $3 \mathrm{~K}$ at $1 \mathrm{~km}$ pixels (approximating MODIS and SLSTR) and $3.5 \mathrm{~K}$ for $375 \mathrm{~m}$ pixels (approximating VIIRS).

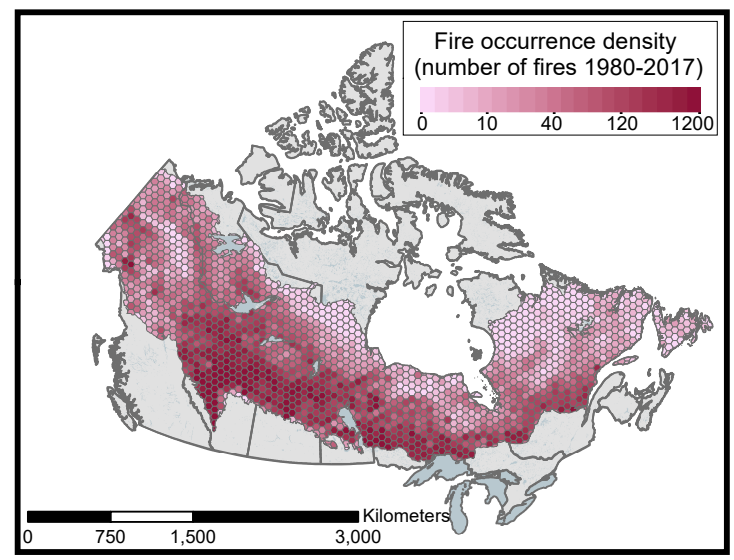

Figure 6. Canada's fire occurrence density (i.e., the number of fires) in the Boreal forest from the National Fire Database [44] from 1980-2017. 
We also looked the spatial patterns of the benchmark 0.2 ha minimum detection threshold with regards to "interface" areas, that is, areas where homes and other critical human-built structures are near or even within wildland fuel areas and are potentially at risk of destruction from wildland fire. For interface locations near urban or industrial structures, we used a composite map of national wildland-urban interface and wildland-industrial interface from Johnston and Flannigan (2018) [45]. We evaluated how much area of interface would receive effective active fire detection from satellite sensors with regard to early detection (i.e., less than 0.2 ha detectible area).

\section{Results}

Airborne fire discovery sizes (Figure 5) are heavily skewed toward smaller values, with a median of 0.2 ha, with $45 \%$ below 0.1 ha and $90 \%$ below 1.0 ha. For the purposes of this study the median value (0.2 ha) was selected as the benchmark fire detection size required to consider the satellite product sufficient for use in initial attack fire suppression. Though the discovery size required for initial attack success varies depending on many other factors (e.g., fire intensity, suppression capacity and response time; $[4,46])$, this median fire discovery fire size from direct airborne patrols provides a conservative threshold for evaluation of model performance in this study. This 0.2 ha threshold is also below the province of Québec's initial attack goal of discovering all fires at less than 0.5 ha [8]. It should be noted that Martell [47] analysed fire sizes at the start of initial attack data from Ontario using data from 1976-1999 which indicated that median fire size was 0.1 ha. We used the 0.2 ha median value using the more recent 1997-2012 data in order to reflect more recent fire management activities.

The results of our modelling exercise showed that FRP attenuation showed an exponential decay relationship with increasing $\operatorname{LAI}\left(\mathrm{R}^{2}=0.98, \alpha=0.66, p<0.001\right.$; Figure 7).

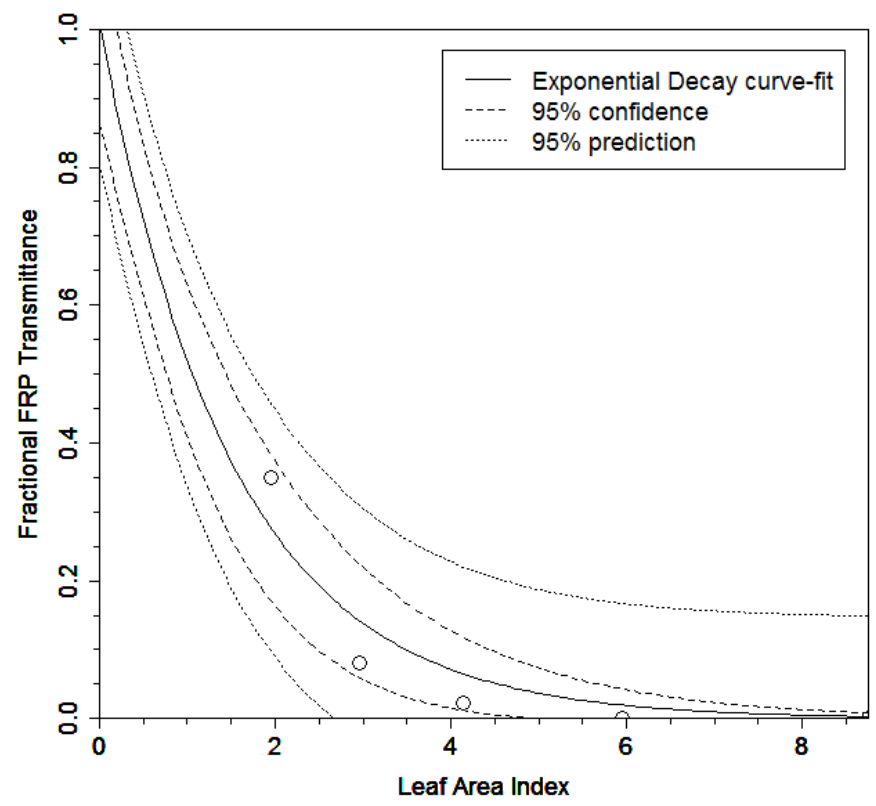

Figure 7. The fractional transmittance of Fire Radiative Power (FRP) with increasing canopy density as described by Leaf Area Index (LAI). An exponential decay function was fit to this data (with an $\mathrm{R}^{2}$ of 0.98 ) in the form: $\mathrm{FRP}_{\text {trans }}=\mathrm{FRP}\left(\mathrm{e}^{-\alpha \mathrm{LAI}}\right)$ where $\alpha$ is a fitted unitless constant of $0.66(p<0.001)$.

We applied Equation (1) to calculate the minimum smouldering detectable area for LAI values ranging from 1 to 8 (Figure 8). We determined the 0.2 ha detection threshold cannot be met for MODIS or SLSTR where LAI is greater 5 or 6 , respectively. However, VIIRS is capable of meeting this threshold up to an LAI of 8 (which is greater than the maximum LAI from the LAI composite maps within our study area). 

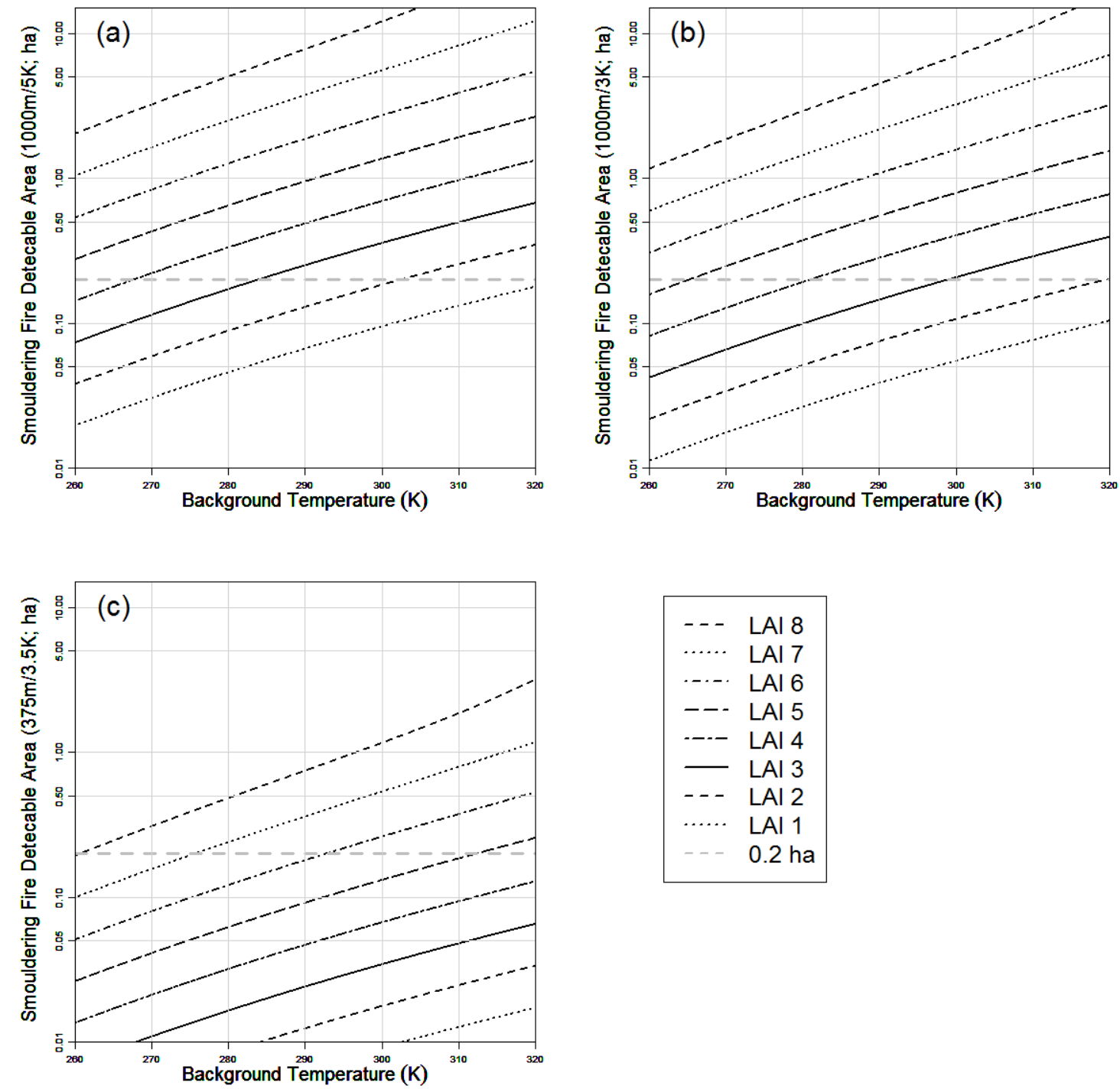

Figure 8. Sub-canopy smouldering fire detectable area (ha) for nadir facing pixels of (a) $1000 \mathrm{~m}$ with $5 \mathrm{~K}$ threshold (MODIS); (b) $1000 \mathrm{~m}$ with $3 \mathrm{~K}$ threshold (SLSTR); and (c) $375 \mathrm{~m}$ with $3.5 \mathrm{~K}$ threshold (VIIRS I-Band). The sub-canopy detectable area varies with canopy density, as described by leaf area index (LAI; Figure 5) and background temperature. For reference the 0.2 ha detection threshold required for fire management is included (dashed gray line). This threshold cannot be met (regardless of background temperature) for $1000 \mathrm{~m}$ pixels with $5 \mathrm{~K}$ threshold where the LAI is > 5, or with a $3 \mathrm{~K}$ threshold where LAI $>6$, however with the $375 \mathrm{~m}$ pixels and $3.5 \mathrm{~K}$ threshold these criteria met up to an LAI value of 8 .

Applying the model spatially, we obtained maps of the sub-canopy potential detectable areas for the three thresholds tested, $5 \mathrm{~K}$ and $3 \mathrm{~K}$ at $1 \mathrm{~km}$ pixels (approximating MODIS and SLSTR) and $3.5 \mathrm{~K}$ for $375 \mathrm{~m}$ pixels (approximating VIIRS), which are presented in Figures 9-11, respectively. For the present study, we focus on maps of maximum potential detectable area (Figures 9c, 10c and 11c), given that it is important to know the worst case scenario for fire detection. As expected, all systems performed better at higher latitudes where the LAI values are generally lower (Figure 3a). For $1000 \mathrm{~m}$ pixels such as MODIS and SLSTR the threshold of $5 \mathrm{~K} 35.8 \%$ of the study area was above the 0.2 ha detection threshold, with a large region of the southern boreal (18.8\% of the study area) requiring areas greater than 0.3 ha for detection (Figure 9c). The $3 \mathrm{~K}$ threshold performs better, however along much of the 
southern boreal forest it is not capable of performing operational detection based on these criteria with $15 \%$ of the study area above 0.2 ha (Figure $10 \mathrm{c}$ ) and only $7.5 \%$ of the study area above 0.3 ha. However, using a $3.5 \mathrm{~K}$ threshold at a spatial resolution of $375 \mathrm{~m}$ (similar to VIIRS I-band), this detection criteria is met for all regions of the North American boreal (Figure 11c).

When areas of insufficient potential detection capacity (i.e., those in pink and red in Figures 9-11) are compared to historic fire occurrence (Figure 6), the impact of these detection limitations is more pronounced in terms of fire management. Of the 132,688 fires that occurred in the study area from 1980-2017, $1 \mathrm{~km}$ sensors such as MODIS and SLSTR would have failed to detect $70.4 \%$ and $44.6 \%$ of the fires in their sub-canopy smouldering phase when they were below the 0.2 ha threshold, based on use of a $5 \mathrm{~K}$ and $3 \mathrm{~K}$ threshold detection temperature above background respectively. Where fire occurrence is more dense (total number of fires in the hexagonal cells $>100$ ), the detection capacity is even lower, with non-detection rates falling to $79.1 \%$ and $52.8 \%$ respectively. According to this simulation however, VIIRS potentially would have successfully detected all the fires in their sub-canopy smouldering phase when they were below the 0.2 ha threshold. When compared to the spatial distribution of Wildland-Urban and Wildland-Industrial Interface areas [45], in these areas use of the $1000 \mathrm{~m}$ spatial resolution data with the $5 \mathrm{~K}$ and $3 \mathrm{~K}$ detection thresholds fails to detect $81.6 \%$ and $56.5 \%$ of fires when they were below the 0.2 ha threshold, respectively.

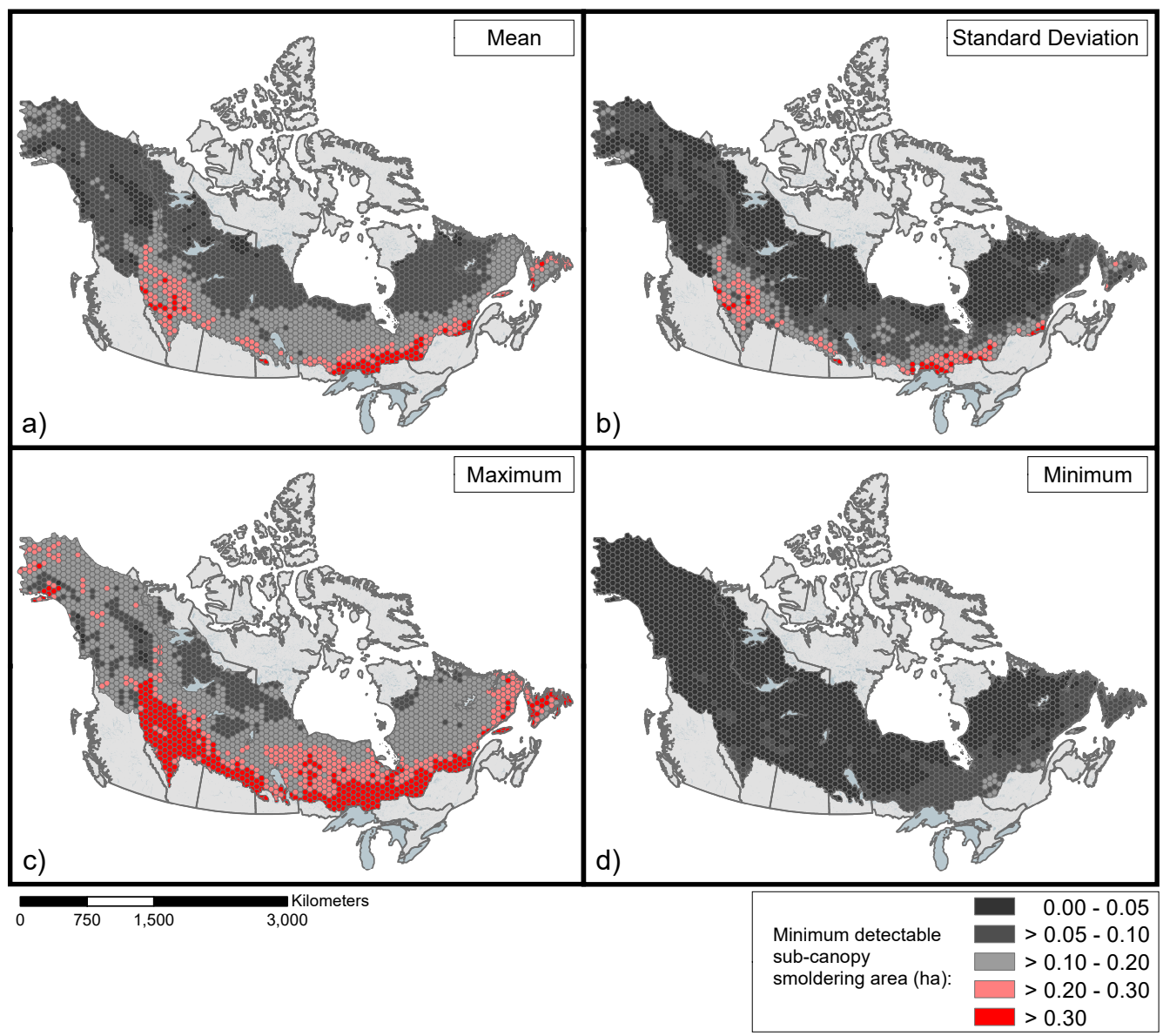

Figure 9. Potential detectable area of sub-canopy smouldering fires for the North American boreal forest, based on $1000 \mathrm{~m}$ pixel size sensor (e.g., MODIS and SLSTR) and an active fire detection threshold equivalent to a $5 \mathrm{~K}$ MWIR channel brightness temperature increase above background. Detectable area was computed monthly for the fire season (May-October) using the LST and LAI (Figure 3) and Equation (1). The monthly data are summarized here by mean (a); standard deviation (b); maximum (c) and minimum (d) for each cell. 


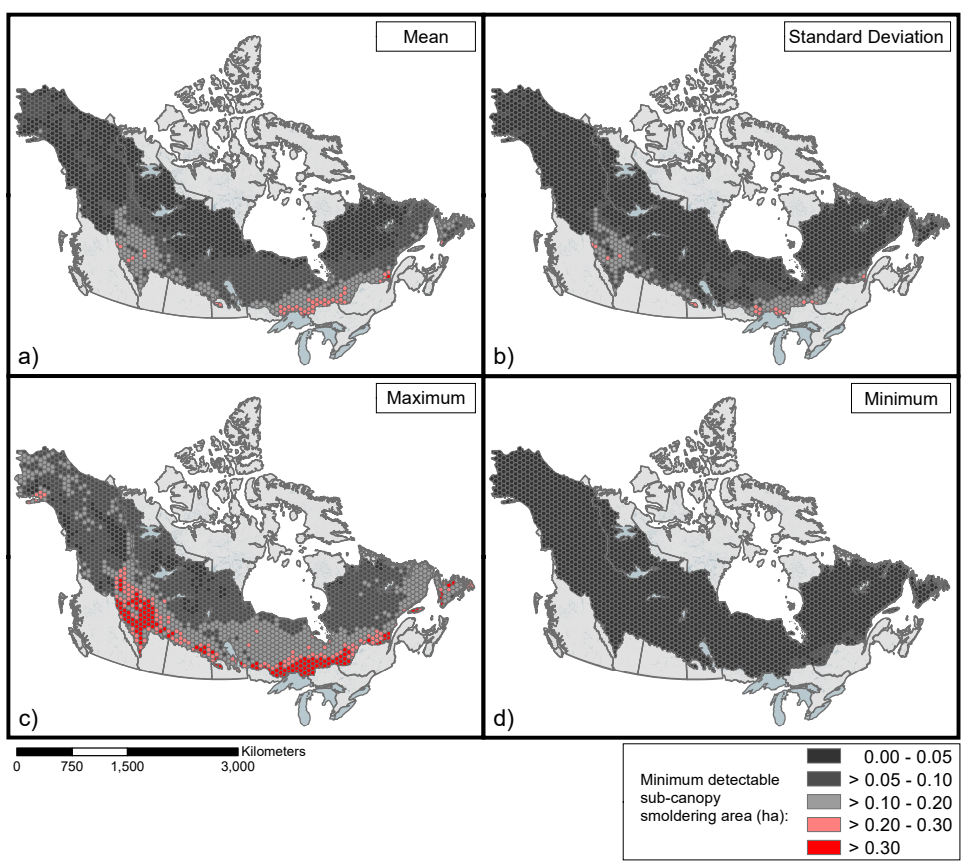

Figure 10. Potential detectable area of sub-canopy smouldering fires for the North American boreal forest, based on $1000 \mathrm{~m}$ pixel size sensor (e.g., MODIS and SLSTR) and an active fire detection threshold equivalent to a $3 \mathrm{~K}$ MWIR channel brightness temperature increase above background. Detectable area was computed monthly for the fire season (May-October) using the LST and LAI (Figure 3) and Equation (1). The monthly data are summarized here by mean (a); standard deviation (b); maximum (c) and minimum (d) for each cell.

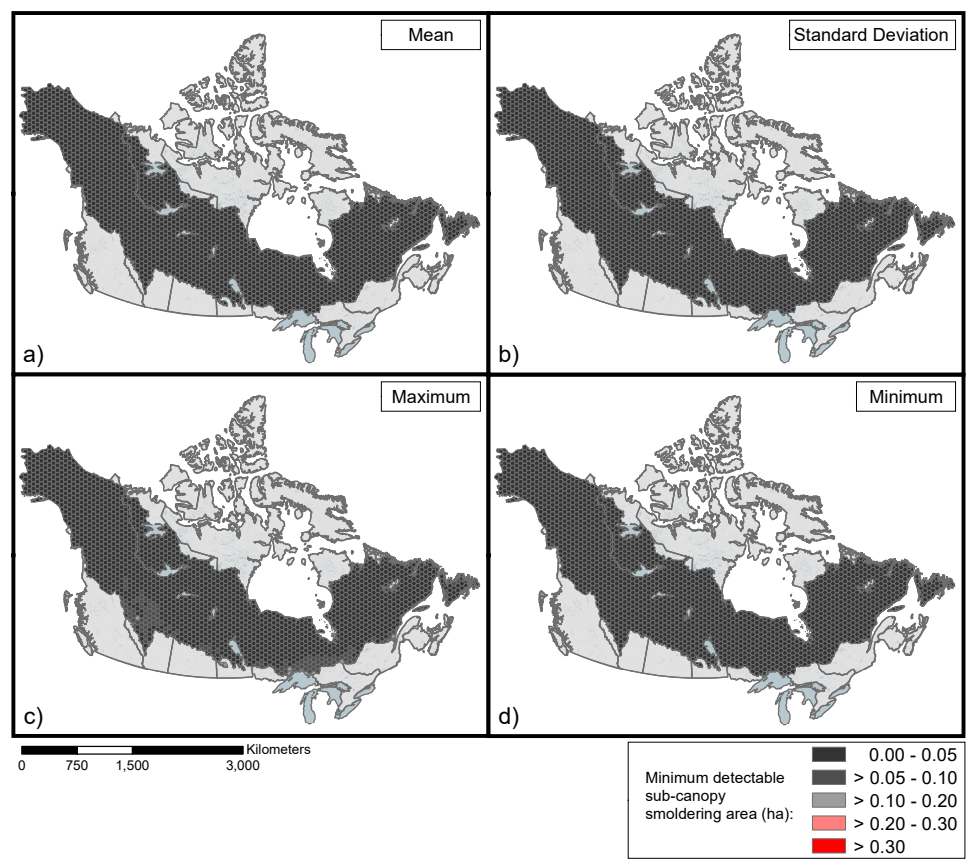

Figure 11. Potential detectable area of sub-canopy smouldering fires for the North American boreal forest, based on $375 \mathrm{~m}$ pixel size sensor (e.g., VIIRS I-Band) and an active fire detection threshold equivalent to a 3.5 K MWIR channel brightness temperature increase above background. Detectable area was computed monthly for the fire season (May-October) using the LST and LAI (Figure 3) and Equation (1). The monthly data are summarized here by mean (a), standard deviation (b), maximum (c) and minimum (d) for each cell. 


\section{Discussion}

To be most useful for supporting early warning of fires to be targeted by initial attack operations, fires in the North American boreal forest should ideally be identified early and responded to rapidly [48]; specifically, when they are smouldering sub-canopy and covering an area less than 0.2 ha. In addition to their lower temperatures and relatively smaller area compared to typical crown fires, the thick canopy present above such surface fires intercepts part of the fire-emitted radiation, making detection more difficult. This study has investigated the ability of current satellite sensors to meet the requirement of detecting a 0.2 ha smouldering surface fire burning below the tree canopy, based on modeling of fire-emitted thermal radiation and the interception of some of the emitted thermal energy by vegetation components in the canopy. We find that coarser spatial resolution sensors (e.g., MODIS and SLSTR with $1 \mathrm{~km}$ pixels at nadir) are incapable of identifying active fires below the specified threshold over much of the boreal forest, with our modeling indicating for example that early detection would have been incapable for around $44-70 \%$ of the historic wildfires in the Canadian boreal forest. We find that sensors with suitably smaller pixel areas such as VIIRS (375 m pixels) are in theory able to meet this criteria over the entire North American boreal. That said, our modeling only indicates that the fires are potentially detectable and there are many phenomena (e.g., cloud cover and limited overpasses per day) that will in fact have prevented early detection in many cases. Thus, our results represent a theoretical ideal and must be interpreted in this context. Real failure rates will likely be significantly higher than we estimate because of departures from this ideal.

We modelled canopy interception of fire energy as a function of LAI, as is common in solar radiation studies. The use of the beer-lambert style model of canopy interception applied here Equation (1) is appropriate for describing mean radiation attenuation of large homogenous areas [49], as found with large satellite pixels $(375$ to $1000 \mathrm{~m})$ in these simulations. However, the physical effect of canopy attenuation of fire energy is perhaps better described as a "blocking" factor (as in Flannigan and Vonder Haar (1986) [19] and Mathews et al. (2016) [20]), where the signal is physically obscured in places and allowed to pass between the canopy structures in others. This in mind, the model developed here is sensitive to the orientation of the canopy elements in the artificial screens used in the experiment. To mitigate these effects an effort was made to apply the canopy elements to the screens in a uniform distribution and the use of visible imagery to characterize LAI ensured that overlapping branches were only considered for their net effect rather than actual leaf area.

Although seasonality is not directly presented in the seasonal summaries of Figures 9-11, there is considerable variation through the fire season. This effect is most prevalent in lower latitudes and can be visualized through examination of the standard deviation maps (Figures 9b, 10b and 11b). Seasonal variability is due to changes in LAI as well as to LST. As result, all systems modelled here perform far better in the early spring in terms of their ability to detect the smallest sub-canopy fires, before the forest green-up occurs and while the background temperatures are much lower (spring performance can generally be interpreted as the "minimum" detectable areas (d) of Figures 9-11). A similar effect occurs in the fall after leaves drop and LST cools.

Notably the criteria for successful detection in this study is the minimum BT increase in the MWIR channel required to pass the initial screening of a contextual active fire detection algorithm, typically between 3 and $5 \mathrm{~K}$. However, once this initial condition is passed there are numerous other spectral-band ratio and contextual tests which must also be passed to confirm the pixel as a fire. It is not certain that a sub-canopy smouldering pixel could pass all of these tests; further research is needed in this area. As mentioned above, it is also important to recall that all of these systems are incapable of detecting active fires when cloud cover is present. The obscuration of cloud is of added importance given that these systems only overpass this region at best a few times per day. Additionally, to achieve the criteria of "detection" for fire suppression it is also critical that the detected fire be reported to the management agencies as soon as possible. In this context, it is not clear that any of the systems tested are capable of reporting a fire rapidly enough to be used as a replacement for traditional fire detection means. 
In the simulations conducted here, a direct nadir facing pixel of 375 or $1000 \mathrm{~m}$ is assumed to evaluate the best case scenario for fire detection for MODIS, SLSTR and VIIRS. It is important to note that the results presented here are only applicable to near nadir pixels given that the spatial resolution of these systems varies (greatly at times) over the width of the swath [50], these effects are less pronounced with VIIRS [14,51] but still present. As a result, much of the swath contains pixels significantly larger than the nominal 375 and $1000 \mathrm{~m}$ for VIIRS, MODIS and SLSTR. Off nadir view angles also increase the path length through the forest canopy which is known to significantly increase the canopy attenuation beyond what is presented in Equation (1) [49]. For these reasons fire detection potential is expected to be significantly lower than for all non-nadir pixels, reaffirming that these results present a best-case scenario for fire detection over the study area.

MODIS and SLSTR are generally unable to detect fires below the required size threshold to best support rapid response operations at lower boreal latitudes and near many interface zones where structural values may potentially be at risk to damage by wildland fire. However, this does not necessarily mean that they lack utility. Interface zones in southern latitudes are typically more densely populated areas where fire detection is most likely to occur through public reporting of fires and therefore satellite detection is not necessarily required. At more northern latitudes, there are far fewer aircraft flights and few people are present on the landscape; in these locations, MODIS and SLSTR may be sufficient for fire detection. In these regions, large fire activity is typically monitored, for this purpose all of the systems simulated here have excellent performance given their strong sensitivity to flaming combustion (Figure $4 \mathrm{a}$ ).

\section{Conclusions}

This study has demonstrated that LEO satellite remote sensing systems operating with pixel sizes around $375 \mathrm{~m}$ (e.g., as offered by the VIIRS I-Bands) offer good potential for early detection of sub-canopy smouldering fires throughout the North American boreal forests and are capable of identifying fires when they are below the 0.2 ha size considered appropriate for initial attack operations. Of course, this can only occur if the satellite overpasses the area when the fire is below that size and if the resulting detections are sufficiently rapidly processed and passed onto fire managers within minutes to perhaps $1 \mathrm{~h}$ of the overpass time (as can occur for example via use of Direct Broadcast receiving stations and local post processing and active fire detection screening). Sensors with far larger pixels, for example the $1000 \mathrm{~m}$ pixel size of MODIS and SLSTR at nadir, offer the potential to achieve a 0.2 ha fire size detection ability only at northern latitudes where forest canopies (and human populations) are less dense.

Author Contributions: Conceptualization, J.M.J. and M.J.W.; Methodology, J.M.J.; Formal Analysis, J.M.J., L.M.J., M.J.W. and A.B.; Investigation, J.M.J., L.M.J., A.B. and A.S.C.; Resources, C.M.; Data Curation, L.M.J., A.B. and A.S.C.; Writing-Original Draft Preparation, J.M.J., L.M.J., M.J.W., A.B. and C.M.; Writing-Review \& Editing, J.M.J. and L.M.J.; Visualization, J.M.J., L.M.J., M.J.W. and A.B.; Supervision, J.M.J. and M.J.W.; Project Administration, J.M.J.; Funding Acquisition, J.M.J. and M.J.W.

Funding: Critical support for this project was provided by the Canadian Space Agency and the European Space Agency. Martin Wooster's work is supported by the UK Natural Environmental Research Council (NERC) and NERC grant NE/J014060/1 supported some of the work described herein.

Acknowledgments: The authors would like to thank John Studens and Tim Lynham for their assistance in the experimental components, Natasha Jurko for her GIS support and Rer. Nat. Markus Tum for providing the LAI data.

Conflicts of Interest: The authors declare no conflict of interest. The funding sponsors had no role in the design of the study; in the collection, analyses, or interpretation of data; in the writing of the manuscript and in the decision to publish the results.

\section{References}

1. Sparhawk, W.N. The use of liability ratings in planning forest fire protection. J. Agric. Res. 1925, 30, 693-762.

2. Martell, D.L.; Sun, H. The impact of fire suppression, vegetation, and weather on the area burned by lightning-caused forest fires in Ontario. Can. J. For. Res. 2008, 38, 1547-1563. [CrossRef] 
3. Duff, T.J.; Tolhurst, K.G. Operational wildfire suppression modelling: A review evaluating development, state of the art and future directions. Int. J. Wildland Fire 2015, 24, 735-748. [CrossRef]

4. Cumming, S.G. Effective fire suppression in boreal forests. Can. J. For. Res. 2005, 35, 772-786. [CrossRef]

5. Podur, J.; Wotton, M. Will climate change overwhelm fire management capacity? Ecol. Model. 2010, 221, 1301-1309. [CrossRef]

6. Houtman, R.M.; Montgomery, C.A.; Gagnon, A.R.; Calkin, D.E.; Dietterich, T.G.; McGregor, S.; Crowley, M. Allowing a wildfire to burn: Estimating the effect on future fire suppression costs. Int. J. Wildland Fire 2013, 22, 871-882. [CrossRef]

7. Fox, D.; Martin, N.; Carrega, P.; Andrieu, J.; Adnès, C.; Emsellem, K.; Ganga, O.; Moebius, F.; Tortorollo, N.; Fox, E. Increases in fire risk due to warmer summer temperatures and wildland urban interface changes do not necessarily lead to more fires. Appl. Geogr. 2015, 56, 1-12. [CrossRef]

8. Developing More Common Language, Terminology and Data Standards for Wildland Fire Management in Canada; Northern Forestry Centre, Canadian Forest Service, Natural Resources Canada: Edmonton, AB, Canada, 2014; p. 45.

9. Bridge, S.R.J.; Miyanishi, K.; Johnson, E.A. A Critical Evaluation of Fire Suppression Effects in the Boreal Forest of Ontario. For. Sci. 2005, 51, 41-50.

10. Roy, D.P.; Boschetti, L.; Justice, C.O.; Ju, J. The collection 5 modis burned area product-Global evaluation by comparison with the modis active fire product. Remote Sens. Environ. 2008, 112, 3690-3707. [CrossRef]

11. Giglio, L.; Randerson, J.T.; van der Werf, G. Analysis of daily, monthly, and annual burned area using the fourth generation global fire emissions database (GFED4). J. Geophys. Res. Biogeosci. 2013, 118, 317-328. [CrossRef]

12. Dragozi, E.; Gitas, I.Z.; Stavrakoudis, D.G.; Theocharis, J.B. Burned area mapping using support vector machines and the fuzcoc feature selection method on VHR IKONOS imagery. Remote Sens. 2014, 6, 12005-12036. [CrossRef]

13. Flannigan, M.D.; Vonder Haar, T.H. Forest fire monitoring using NOAA satellite AVHRR. Can. J. For. Res. 1986, 16, 975-982. [CrossRef]

14. Schroeder, W.; Oliva, P.; Giglio, L.; Csiszar, I.A. The new VIIRS $375 \mathrm{~m}$ active fire detection data product: Algorithm description and initial assessment. Remote Sens. Environ. 2014, 143, 85-96. [CrossRef]

15. Giglio, L.; Schroeder, W.; Justice, C.O. The collection 6 modis active fire detection algorithm and fire products. Remote Sens. Environ. 2016, 178, 31-41. [CrossRef]

16. NASA. Fire Information for Resource Management System (FIRMS). In Land, Atmosphere near Real-Time Capability for EOS (LANCE) System; NASA/GSFC/Earth Science Data and Information System (ESDIS), Funding Provided by NASA/HQ. Available online: https: / / earthdata.nasa.gov/ earth-observation-data / near-real-time (accessed on 9 August 2018).

17. Freeborn, P.H.; Wooster, M.J.; Roberts, G.; Malamud, B.D.; Xu, W. Development of a virtual active fire product for Africa through a synthesis of geostationary and polar orbiting satellite data. Remote Sens. Environ. 2009, 113, 1700-1711. [CrossRef]

18. Zhang, T.; Wooster, M.J.; Xu, W. Approaches for synergistically exploiting VIIRS I-and M-Band data in regional active fire detection and FRP assessment: A demonstration with respect to agricultural residue burning in Eastern China. Remote Sens. Environ. 2017, 198, 407-424. [CrossRef]

19. Flannigan, M.D.; Vonder Haar, T.H. Forest fire monitoring using the NOAA satellite series. In Proceedings of the Second Conference on Satellite Meteorology/Remote Sensing and Applications, Williamsburg, VA, USA, 13-16 May 1986; pp. 168-172.

20. Mathews, B.J.; Strand, E.K.; Smith, A.M.S.; Hudak, A.T.; Dickinson, M.B.; Kremens, R.L. Laboratory experiments to estimate interception of infrared radiation by tree canopies. Int. J. Wildland Fire 2016, 25, 1009-1014. [CrossRef]

21. Wooster, M.J.; Roberts, G.; Perry, G.L.W.; Kaufman, Y.J. Retrieval of biomass combustion rates and totals from fire radiative power observations: FRP derivation and calibration relationships between biomass consumption and fire radiative energy release. J. Geophys. Res. Atmos. 2005, 110. [CrossRef]

22. Wooster, M.J.; Zhukov, B.; Oertel, D. Fire radiative energy for quantitative study of biomass burning: Derivation from the BIRD experimental satellite and comparison to MODIS fire products. Remote Sens. Environ. 2003, 86, 83-107. [CrossRef] 
23. Ichoku, C.; Ellison, L. Global top-down smoke-aerosol emissions estimation using satellite fire radiative power measurements. Atmos. Chem. Phys. 2014, 14, 6643-6667. [CrossRef]

24. Mota, B.; Wooster, M.J. A new top-down approach for directly estimating biomass burning emissions and fuel consumption rates and totals from geostationary satellite fire radiative power (FRP). Remote Sens. Environ. 2018, 206, 45-62. [CrossRef]

25. Breshears, D.D.; Rich, P.M.; Barnes, F.J.; Campbell, K. Overstory-Imposed Heterogeneity in Solar Radiation and Soil Moisture in a Semiarid Woodland. Ecol. Appl. 1997, 7, 1201-1215. [CrossRef]

26. Ball, R.A.; Purcell, L.C.; Carey, S.K. Evaluation of Solar Radiation Prediction Models in North America. Agron. J. 2004, 96, 391-397. [CrossRef]

27. Bewley, D.; Pomery, J.W.; Essery, R.L.H. Solar Radiation Transfer through a Subarctic Shrub Canopy. Arct. Antarct. Alp. Res. 2007, 39, 365-374. [CrossRef]

28. Johnston, J.M.; Wooster, M.J.; Lynham, T.J. Experimental Confirmation of the MWIR and LWIR Greybody Hypothesis for Vegetation Fire Flame Emissivity. Int. J. Wildland Fire 2014, 23, 463-479. [CrossRef]

29. Ohlemiller, T.J. Smoldering combustion: Sections 2-11. In SFPE Handbook of Fire Protection Engineering, 2nd ed.; National Fire Protection Association, Society of Fire Protection Engineers: Quincy, MA, USA, 1995.

30. Van Wagner, C. Christmas trees like water. In Fire Fighting in Canada; 1962; p. 16.

31. Chen, J.M.; Pavlic, G.; Brown, L.; Cihlar, J.; Leblanc, S.G.; White, H.P.; Hall, R.J.; Peddle, D.R.; King, D.J.; Trofymow, J.A.; et al. Derivation and validation of Canada-wide coarse-resolution leaf area index maps using high-resolution satellite imagery and ground measurements. Remote Sens. Environ. 2002, 80, 165-184. [CrossRef]

32. Chen, J.M.; Black, T.A. Measuring leaf area index of plant canopies with branch architecture. Agric. For. Meteorol. 1991, 57, 1-12. [CrossRef]

33. Zheng, G.; Moskal, L.M. Retrieving leaf area index (LAI) using remote sensing: Theories, methods and sensors. Sensors 2009, 9, 2719-2745. [CrossRef] [PubMed]

34. Black, T.A.; Chen, J.-M.; Lee, X.; Sagar, R.M. Characteristics of shortwave and longwave irradiances under a Douglas-fir forest stand. Can. J. For. Res. 1991, 21, 1020-1028. [CrossRef]

35. Frazer, G.W.; Canham, C.D.; Lertzman, K.P. Gap Light Analyzer (GLA), Version 2.0: Imaging Software to Extract Canopy Structure and Gap Light Transmission Indices from True-Colour Fisheye Photographs, Users' Manual and Program Documentation; Simon Fraser University: Burnaby, BC, Canada; Institute of Ecosystem Studies: Millbrook, NY, USA, 1999.

36. FAO. Global Ecofloristic Zones Mapped by the United Nations Food and Agricultural Organization. FAO, Adapted by Aaron Ruesch and Holly K. Gibbs. 2008. Available online: https:/ / databasin.org/datasets / dc4f6efd1fa84ea99df61ae9c5b3b763.2000 (accessed on 9 August 2018).

37. Jenness, J. Repeating Shapes for ArcGIS; Jenness Enterprises: Flagstaff, AZ, USA, 2012. Available online: http:/ / www.jennessent.com/arcgis/repeat_shapes.htm (accessed on 9 August 2018).

38. Giglio, L.; Descloitres, J.; Justice, C.O.; Kaufman, Y.J. An Enhanced Contextual Fire Detection Algorithm for MODIS. Remote Sens. Environ. 2003, 87, 273-282. [CrossRef]

39. Wooster, M.J.; Xu, W.; Nightingale, T. Sentinel-3 SLSTR active fire detection and FRP product: Pre-launch algorithm development and performance evaluation using MODIS and ASTER datasets. Remote Sens. Environ. 2012, 120, 236-254. [CrossRef]

40. Wotton, B.; Gould, J.; McCaw, W.; Cheney, N.; Taylor, S. Flame temperature and residence time of fires in dry eucalypt forest. Int. J. Wildland Fire 2012, 21, 270-281. [CrossRef]

41. Kremens, R.; Faulring, J.; Hardy, C. Measurement of the time-temperature and emissivity history of the burn scar for remote sensing applications. In Proceedings of the 5th Symposium on Fire and Forest Meteorology and the 2nd International Wildland Fire Ecology and Fire Management Congress, American Meteorological Society, Orlando, FL, USA, 16-20 November 2003.

42. Dozier, J. A method for satellite identification of surface temperature fields of subpixel resolution. Remote Sens. Environ. 1981, 11, 221-229. [CrossRef]

43. Wan, Z.; Hook, S.; Hulley, G. MOD11B3 MODIS/Terra Land Surface Temperature/Emissivity Monthly L3 Global 6 km SIN Grid V006, [Data set]. NASA EOSDIS LP DAAC 2015. [CrossRef]

44. Canadian Forest Service. Canadian National Fire Database-Agency Fire Data. Dataset; Natural Resources Canada/Canadian Forest Service/Northern Forestry Centre: Edmonton, AB, Canada, 2017. Available online: http:/ / cwfis.cfs.nrcan.gc.ca/ha/nfdb (accessed on 9 August 2018). 
45. Johnston, L.M.; Flannigan, M.D. Mapping Canadian wildland fire interface areas. Int. J. Wildland Fire 2018, 27, 1-14. [CrossRef]

46. Wotton, B.M.; Flannigan, M.D.; Marshall, G.A. Potential climate change impacts on fire intensity and wildfire suppression thresholds in Canada. Environ. Res. Lett. 2017, 12, 095003. [CrossRef]

47. Martell, D.L. Forest Fire Management. In Forest Fires; Academic Press: New York, NY, USA, 2001; pp. 527-583.

48. Morin, A.A.; Albert-Green, A.; Woolford, D.G.; Martell, D.L. The use of survival analysis methods to model the control time of forest fires in Ontario, Canada. Int. J. Wildland Fire 2015, 24, 964-973. [CrossRef]

49. Hellström, R.Å. Forest cover algorithms for estimating meteorological forcing in a numerical snow model. Hydrol. Process. 2000, 14, 3239-3256. [CrossRef]

50. Freeborn, P.; Wooster, M.J.; Roberts, G. Addressing the spatiotemporal sampling design of MODIS to provide estimates of the fire radiative energy emitted from Africa. Remote Sens. Environ. 2011, 115, 475-489. [CrossRef]

51. Wolfe, R.E.; Lin, G.; Nishihama, M.; Tewari, K.P.; Tilton, J.C.; Isaacman, A.R. Suomi NPP VIIRS prelaunch and on-orbit geometric calibration and characterization. J. Geophys. Res. Atmos. 2013, 118, 11508-11521. [CrossRef]

(C) 2018 by the authors. Licensee MDPI, Basel, Switzerland. This article is an open access article distributed under the terms and conditions of the Creative Commons Attribution (CC BY) license (http:/ / creativecommons.org/licenses/by/4.0/). 